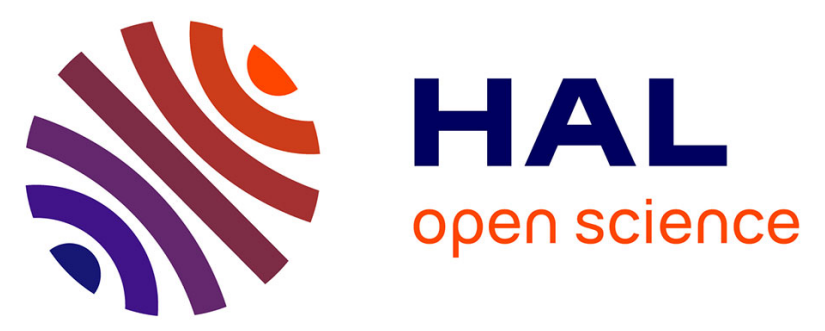

\title{
Coherent Supercontinuum Generation in a Silicon-Germanium Waveguide in the Mid Infrared
}

Milan Sinobad, Christelle Monat, Barry Luther-Davies, Pan Ma, Stephen

Madden, David J. Moss, Arnan Mitchell, Regis Orobtchouk, Alberto Della

Torre, Salim Boutami, et al.

\section{To cite this version:}

Milan Sinobad, Christelle Monat, Barry Luther-Davies, Pan Ma, Stephen Madden, et al.. Coherent Supercontinuum Generation in a Silicon-Germanium Waveguide in the Mid Infrared. Mid-Infrared Coherent Sources, Mar 2018, Strasbourg, France. pp.MT2C.8, 10.1364/MICS.2018.MT2C.8 . hal02006487

\section{HAL Id: hal-02006487 \\ https://hal.science/hal-02006487}

Submitted on 12 Sep 2021

HAL is a multi-disciplinary open access archive for the deposit and dissemination of scientific research documents, whether they are published or not. The documents may come from teaching and research institutions in France or abroad, or from public or private research centers.
L'archive ouverte pluridisciplinaire $\mathbf{H A L}$, est destinée au dépôt et à la diffusion de documents scientifiques de niveau recherche, publiés ou non, émanant des établissements d'enseignement et de recherche français ou étrangers, des laboratoires publics ou privés. 


\title{
Coherent supercontinuum generation in a silicon- germanium waveguide in the mid infrared
}

\author{
Milan Sinobad ${ }^{1,2, *}$, Christelle Monat ${ }^{1}$, Barry Luther-Davies ${ }^{3}$, Pan Ma $^{3}$, Stephen Madden ${ }^{3}$, David J. Moss ${ }^{4}$, \\ Arnan Mitchell ${ }^{2}$, Regis Orobtchouk ${ }^{1}$, Alberto Della Torre ${ }^{1}$, Salim Boutami ${ }^{5}$, Jean-Michel Hartmann ${ }^{5}$, \\ Jean-Marc Fedeli ${ }^{5}$, Christian Grillet ${ }^{1}$

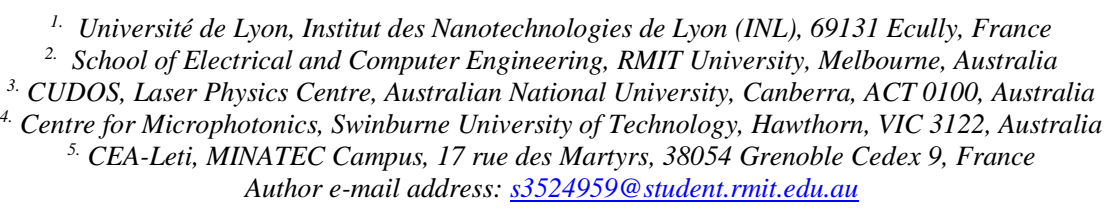

\begin{abstract}
We report high brightness coherent supercontinuum extending from 2.8 to $5.0 \mu \mathrm{m}$ in an air cladded $\mathrm{Si}_{0.6} \mathrm{Ge}_{0.4} / \mathrm{Si}$ waveguide with all-normal dispersion. Supercontinuum is generated by pumping with $\sim 200 \mathrm{fs}$ pulses at $3.8 \mu \mathrm{m}$. Dispersion engineering and low propagation loss $(\sim 0.5 \mathrm{~dB} / \mathrm{cm}$ at $3.8 \mu \mathrm{m})$ allowed us to achieve more than $5 \mathrm{~mW}$ useful on-chip average power.

OCIS codes: (320.6629) Supercontinuum generation; (190.4390) Nonlinear optics, integrated optics; (140.3070) Infrared and far-infrared lasers.
\end{abstract}

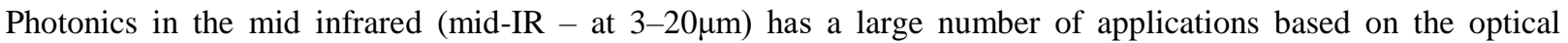
detection of molecules that can be readily identified through measuring their strong fundamental absorption lines in this band $[1,2]$. To perform this measurement, supercontinuum (SC) sources are particularly well-suited, since they allow for reliable molecule detection by accessing in parallel their distinct absorption lines. Broad mid-IR supercontinuum is traditionally generated via soliton fission, as obtained by pumping a nonlinear waveguide with an anomalous dispersion, close to the zero dispersion wavelength (ZDW) [3, 4]. Although these sources have a large spectral power density across a wide wavelength band and a relatively good power budget, the soliton fission process is triggered by noise seeded modulation instability, which degrades the coherence of the related source. However, many applications such as optical coherence tomography, coherent Raman and anti-stokes Raman spectroscopy, broadband time-resolved pump-probe spectroscopy or ultra-short pulse generation, require a broadband phase coherent source [5-7].

Stable and coherent SC generation can be achieved by exploiting coherent self-phase modulation and optical wave breaking effects in a waveguide with low all-normal dispersion [5]. The required pump power however tends to be larger in this dispersion regime, which has precluded its widespread use in applications. In this work, we report SC in the mid-IR spanning from $2.78-5.05 \mu \mathrm{m}$ by launching $18.3 \mathrm{~mW}$ pump power into a dispersion-engineered lowloss "air clad" $\mathrm{Si}_{0.6} \mathrm{Ge}_{0.4}$ waveguide with all-normal group velocity dispersion (Fig $1 \mathrm{~b}$ - inset). The waveguide consists of a $2.7 \mu \mathrm{m}$ thick and $3.5 \mu \mathrm{m}$ wide $\mathrm{Si}_{0.6} \mathrm{Ge}_{0.4}$ ridge on a silicon substrate. It was engineered to have singlemode operation and low normal dispersion with low effective area and strong mode confinement $(>94 \%$ at $3.8 \mu \mathrm{m}$, see Fig $1 \mathrm{~b}$ - inset). Although being air-clad, a propagation loss as low as $0.4 \mathrm{~dB} / \mathrm{cm}$ in the broad range from 3.8 to $5.0 \mu \mathrm{m}$, has been reported in these waveguides [8].
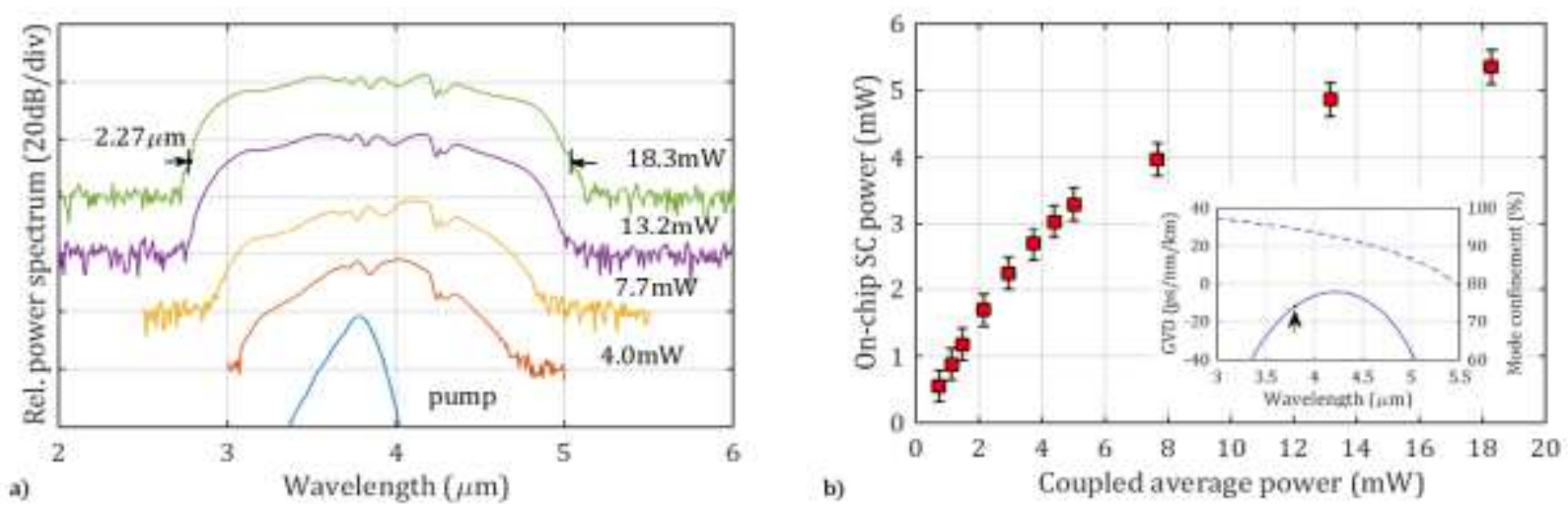

Figure 1 a) Output spectra measured at different coupled power, b) Measured on-chip SC power versus coupled power. Calculated group velocity dispersion (solid blue line) and mode confinement (dashed blue line) are show in the inset. 
Supercontinuum generation is achieved by pumping the waveguide with $\approx 200 \mathrm{fs}$ TM polarized pulses from a midinfrared MIROPA-fs optical parametric amplifier at a repetition rate of $63 \mathrm{MHz}$. Using a $2 \mathrm{~cm}$ long waveguide pumped at $3.8 \mu \mathrm{m}$ in the normal dispersion regime we obtain the spectra shown in Fig 1a. The supercontinuum spectra achieved here are smoother than that traditionally obtained in the anomalous dispersion regime, and the remaining fluctuations observed on Fig. 1a are typical from self-phase modulation. When pumped with $18.3 \mathrm{~mW}$ coupled average pump power, a $2.27 \mu \mathrm{m}$ bandwidth at $-30 \mathrm{~dB}(2.78-5.05 \mu \mathrm{m})$ and a $1.84 \mu \mathrm{m}$ bandwidth at $-10 \mathrm{~dB}$ level are achieved. The lower propagation losses achieved here compared with previous results $[9,10]$, enabled us to generate SC at much reduced pump intensity, thereby limiting the impact of high-order nonlinear absorption (Fig 1b), resulting in an increased SC on-chip power $(>5 \mathrm{~mW})$.

In summary, we report the first supercontinuum generated in all-normal dispersion regime in any CMOS compatible platform. Supercontinuum is spanning across the relevant mid-IR wavelength range from $3-5 \mu \mathrm{m}$, where most molecules have fingerprints, enabling coherent spectroscopy applications. The generated average mid-IR power exceeds that produced so far by other Si-based platforms. This establishes silicon germanium-on-silicon as a promising platform for integrated nonlinear photonics in the mid-IR.

Acknowledgments: Agence Nationale de la Recherche (ANR) MIRSiCOMB (ANR-17-CE24-0028), European ERC grant GRAPHICS (648546); We acknowledge the support of the International Associated Laboratory in Photonics between France and Australia (LIA ALPhFA), CM acknowledges the support of the Institut Universitaire de France.

\section{References}

[1] R. Soref, "Mid-infrared photonics in silicon and germanium," Nature Photonics, vol. 4, pp. 495-497, 2010.

[2] L. Zhang, A. M. Agarwal, L. C. Kimerling, and J. Michel, "Nonlinear group IV photonics based on silicon and germanium: from nearinfrared to mid-infrared," Nanophotonics, vol. 3, pp. 247-268, 2014.

[3] Y. Yu, X. Gai, P. Ma, K. Vu, Z. Yang, R. Wang, et al., "Experimental demonstration of linearly polarized 2-10 mum supercontinuumgeneration in a chalcogenide rib waveguide," Opt Lett, vol. 41, pp. 958-61, Mar 012016.

[4] C. R. Petersen, U. Møller, I. Kubat, B. Zhou, S. Dupont, J. Ramsay, et al., "Mid-infrared supercontinuum covering the 1.4-13.3 $\mu \mathrm{m}$ molecular fingerprint region using ultra-high NA chalcogenide step-index fibre," Nature Photonics, vol. 8, pp. 830-834, 2014.

[5] A. M. Heidt, "Pulse preserving flat-top supercontinuum generation in all-normal dispersion photonic crystal fiber," J. Opt. Soc. Am. B, De cember 26, 20092010

[6] A. M. Heidt, A. Hartung, G. W. Bosman, P. Krok, E. G. Rohwer, H. Schwoerer, et al., "Coherent octave spanning near-infrared and visible supercontinuum generation in all-normal dispersion photonic crystal fibers," Optics express, vol. 19, pp. 3775-3787, 20112011.

[7] A. Hartung, A. M. Heidt, and H. Bartelt, "Nanoscale all-normal dispersion optical fibers for coherent supercontinuum generation at ultraviolet wavelengths," Optics express, vol. 20, pp. 13777-13788, 2012.

[8] M. Sinobad, P. Ma, B. Luther-Davies, D. Allioux, R. Orobtchouk, D. J. Moss, et al., "Broadband mid-infrared supercontinuum generation in low loss dispersion engineered silicon-germanium waveguide," CLEO Europe 2017, 2017.

[9] L. Carletti, P. Ma, Y. Yu, B. Luther-Davies, D. Hudson, C. Monat, et al., "Nonlinear optical response of low loss silicon germanium waveguides in the mid-infrared," Opt Express, vol. 23, pp. 8261-71, Apr 062015.

[10] L. Carletti, M. Sinobad, P. Ma, Y. Yu, D. Allioux, R. Orobtchouk, et al., "Mid-infrared nonlinear optical response of Si-Ge waveguides with ultra-short optical pulses," Opt Express, vol. 23, pp. 32202-14, Dec 142015. 